\title{
Sobre a busca por equivalentes funcionais em um corpus comparável português-inglês de críticas gastronômicas
}

\section{On the search for functional equivalents in a comparable Portuguese-English corpus of restaurant reviews}

\author{
Rozane R. Rebechi ${ }^{*}$ \\ Giulia Rotava Schabbach** \\ Patrícia Helena Freitag ${ }^{* * *}$
}

\footnotetext{
*Professora na graduação e pós-graduação do Instituto de Letras da Universidade Federal do Rio Grande do Sul. E-mail: rozane.rebechi@ufrgs.br

"* Graduanda do Instituto de Letras da Universidade Federal do Rio Grande do Sul. E-mail: schabbach.giulia@gmail.com

s*** Doutoranda pelo Programa de Pós-Graduação em Letras da Universidade Federal do Rio Grande do Sul. E-mail: patriciafreitag@gmail.com
}

TradTerm, São Paulo, v.37, n. 2, janeiro/2021, p. 430-459

Número Especial - Linguística de Corpus 
Resumo: 0 objetivo deste artigo é apresentar a metodologia adotada na busca por equivalentes para os termos e fraseologias que compõem um glossário bilíngue português-inglês de críticas gastronômicas. As traduções de textos culinários muitas vezes revelam apagamento de elementos culturais e perda de convencionalidade, possivelmente devido à escassez de obras de referência na área. Para auxiliar tradutores e redatores a produzirem textos que levem em conta a naturalidade e as diferenças entre línguas e culturas, compilamos um corpus comparável português brasileiro-inglês estadunidense de críticas gastronômicas e fizemos um levantamento de termos funcionalmente equivalentes. Apoiamo-nos nos pressupostos da Linguística de Corpus e da Teoria Funcionalista da Tradução. As análises quantitativa e qualitativa mostraram que, em diferentes graus nos dois idiomas, esse gênero textual faz uso expressivo de linguagem metafórica e idiomática na descrição de serviços, ambientes e pratos.

Palavras-chave: Crítica gastronômica; Terminologia; Tradução; Linguística de Corpus.

Abstract: This paper aims to present the methodology used to search for functional equivalents of terms and clusters comprising a Portuguese-English glossary of restaurant reviews. The translation of culinary texts frequently disregards cultural markers and conventionalities, perhaps due to the scarcity of reference works in this field. In order to help translators and writers take into consideration fluency and the differences in languages and cultures, we compiled a comparable corpus of restaurant reviews and retrieved terms which are functionally equivalent in both languages. Corpus linguistics and the Functionalist Approach to Translation underlie our study. From the quantitative and the qualitative analyses, we learned that this textual genre makes significant use of metaphoric and idiomatic language in the descriptions of service, ambience and food, although to different degrees in the two languages.

Keywords: Restaurant review; Terminology; Translation; Corpus Linguistics.

TradTerm, São Paulo, v.37, n. 2, janeiro/2021, p. 430-459

Número Especial - Linguística de Corpus

www.revistas.usp.br/tradterm 


\section{Introdução}

A culinária é um tema recorrente em blogs, livros, revistas e programas de TV, mas não desfruta de semelhante status no ambiente acadêmico. Afinal, o tema foi por muito tempo considerado inferior se comparado à literatura e a outras artes (CAPATTI, MONTANARI 1999). Contudo, esse quadro está passando por mudanças consideráveis nas últimas décadas, o que pode ser comprovado por pesquisas como as de Gerhardt et al. (2013), Jurafsky (2014) e Tigner e Carruth (2017), que abordam a culinária pelo viés científico.

Com a globalização, as pessoas passaram a ter acesso a conteúdos criados em todo o mundo e, por isso, espera-se que textos culinários - críticas gastronômicas, receitas, cardápios etc. - também sejam constantemente traduzidos de uma língua para outra. Diante dessa demanda, não surpreende o aumento do interesse em analisar o tema do ponto de vista da tradução e da terminologia bilíngue (TeIXeIRA 2008; ReBECHI 2015; ReBECHI, MOURA 2017; Temmerman, Dubols 2017).

Com fins tradutórios, e por meio de uma metodologia empírica respaldada pela Linguística de Corpus (LC) (MCENeRY, HARDIE 2012; BowKer, PEARSON 2002), este artigo visa descrever a compilação, o processamento e a análise de um corpus comparável composto por críticas gastronômicas escritas originalmente em português brasileiro e em inglês estadunidense, tendo, como produto final, um glossário de livre acesso que auxilie tradutores e redatores da área na produção de textos culinários convencionais (NORD 2012), especialmente críticas e resenhas gastronômicas e cardápios, que fluam com naturalidade na língua inglesa, respeitando-se as especificidades do gênero na língua de chegada. Nesse glossário, o verbete é composto essencialmente de entrada em português e um ou mais equivalentes em inglês, seguidos de exemplo de uso autêntico extraído do corpus. Quando julgado necessário, incluímos definições e comentários que orientem o consulente no tratamento das diferenças culturais.

TradTerm, São Paulo, v.37, n. 2, janeiro/2021, p. 430-459

Número Especial - Linguística de Corpus

www.revistas.usp.br/tradterm 


\section{Crítica gastronômica como gênero textual}

0 estudo de gêneros textuais não é recente. Impulsionadas por Swales (1990), pesquisas sobre o texto acadêmico permeiam trabalhos como os de Biber et al. (2004) e Biber e Barbieri (2007), apenas para citar alguns autores que se utilizam de ferramentas de corpus em suas análises. Observa-se, portanto, certa predileção pelo estudo de gêneros de maior prestígio. Em relação aos textos dedicados à síntese e avaliação de obras ou produtos, percebemos certo movimento em relação à resenha de livros e artigos científicos, talvez como consequência do vínculo direto com o mundo do conhecimento e das pesquisas. Trabalhos como o de Ruiz e Faria (2012), que trata da intertextualidade observada no gênero acadêmico, e o de Junqueira (2013), que examina padrões retóricos interculturais em resenhas de livros de Linguística Aplicada escritos em inglês e em português brasileiro, demonstram interesse em questões de linguagem e cultura presentes em textos científicos. Já em relação à análise de críticas gastronômicas e de softwares, por exemplo, Blank (2007) afirma que a escassa literatura tende a se limitar ao impacto das avaliações nas vendas de produtos e serviços. Com foco nas avaliações de softwares e restaurantes, o autor inova ao propor uma análise textual com viés sociológico, e, portanto, suas observações permeiam diversas etapas de nossa pesquisa.

Definidas por Blank (2007: 7) como “[...] resumos e avaliações públicas que ajudam os leitores a escolher, compreender ou apreciar produtos ou espetáculos"1, 2, as críticas não só sintetizam as características de determinada mercadoria ou serviço, mas também avaliam se as expectativas do público são atingidas. Em outras palavras, segundo esse autor, a resenha crítica responde a duas perguntas: “O que é?" e "É bom?" (BLANk 2007: 7). Naturalmente, a observação do crítico não pressupõe consenso, já que determinada mercadoria ou serviço pode ser positivamente avaliada por um, e criticada por outro. Além disso, “[a]s críticas são produzidas por instituições com memórias institucionais

\footnotetext{
1 No original: "[...] public summaries and evaluations that assist readers to be more knowledgeable in their choice, understanding, or appreciation of products or performances." 2 É de nossa autoria a tradução de citações neste artigo.
}

TradTerm, São Paulo, v.37, n. 2, janeiro/2021, p. 430-459

Número Especial - Linguística de Corpus

www.revistas.usp.br/tradterm 
e conjuntos de procedimentos operacionais padrão"3 (BLANK 2007), e esse processo de produção também pode interferir no conteúdo de textos desse gênero. Ainda assim, a influência da crítica sobre o público é grande ao ponto de alçar um estabelecimento ou produto à fama ou destruir sua imagem, atuando, portanto, sobre o lucro e a reputação das empresas.

No que tange à gastronomia, a influência do crítico foi imortalizada em diversos filmes. Ratatouille (BIRD 2007), por exemplo, narra a história do ratinho cozinheiro Rémy, que recebe aparições de Auguste Gusteau, chef que teria morrido após receber uma dura crítica de Anton Ego. Infelizmente, esse drama não se restringe à ficção. Críticas negativas, ou o receio delas, têm impacto na vida real, como no caso do perfeccionista Bernard Loiseau, que se suicidou após receber avaliações negativas do seu estrelado restaurante francês La Côte d'Or (ADLER 2003). Mas, para exercer tamanha influência, o crítico precisa ter credibilidade.

Diante da infinidade de meios que divulgam opiniões de usuários, sendo o site TripAdvisor o maior repositório de feedback sobre restaurantes, hotéis e outros conteúdos relacionados ao turismo, poderíamos questionar o que ainda leva os periódicos a publicar avaliações desses estabelecimentos. Blank (2007) explica que esse gênero textual atrai a atenção daqueles que não confiam no julgamento de amigos, vendedores ou anúncios na hora de escolher entre diferentes ofertas de produtos e serviços, e que buscam avaliações objetivas e convincentes, escritas por especialistas da área em questão.

Apesar de os críticos especializados usarem estilos próprios nos textos que redigem, além de respeitarem as normas das publicações para as quais escrevem - sendo o limite de palavras apenas uma delas -, alguns traços permeiam seus relatos, que se caracterizam por apresentar ao leitor " [...] as complexidades e nuances do produto sob avaliação"4 (BLANK 2007: 30). No que tange às críticas gastronômicas, os avaliadores focam basicamente três aspectos: alimento (comida e bebida), ambiente e serviço (SCHIRA 2015). Além

\footnotetext{
${ }^{3}$ No original: "Reviews are produced by institutions with institutional memories and sets of standard operating procedures."

${ }^{4}$ No original: "[...] the complexities and nuances of the product under review".

TradTerm, São Paulo, v.37, n. 2, janeiro/2021, p. 430-459

Número Especial - Linguística de Corpus

www.revistas.usp.br/tradterm
} 
de explicitar sua impressão em relação a esses elementos, o especialista apresenta argumentos que justificam seu parecer. Portanto, às perguntas " $O$ que é?" e "É bom?", poderíamos acrescentar uma terceira: "Por quê?”. E essas perguntas podem ser respondidas de formas bastante distintas em cada língua e cultura, resultando inclusive em grande diferença na extensão dos textos, como veremos na seção 4.1 deste artigo.

Um olhar mais atento às críticas gastronômicas em português e em inglês revelou diferenças que extrapolam questões terminológicas nas duas línguas. Primeiro, evidenciou-se maior variedade lexical em língua inglesa do que em português na avaliação dos elementos que permeiam a crítica. Segundo, o uso de metáforas e idiomatismos, recurso frequentemente observado nesse gênero textual, também se mostrou mais recorrente nos textos em inglês, os quais empregam um estilo semelhante ao da crônica (PUDLOWSKI 2012), conforme ilustrado pelo excerto abaixo, extraído de uma crítica de um restaurante chinês que serve dim sum publicada no jornal The New York Times ${ }^{5}$ :

Every day hundreds of [little piggies] are wheeled around a dining room that would dwarf some nations' airports. It's a wonder that any make it, unsnatched, to the far side, but somehow the dim-sum cart ladies manage it, like Jesus multiplying the loaves and fishes... ${ }^{6}$ (NAGLE 2019)

Apesar de guardarem características prototípicas do gênero textual ao qual pertencem, as críticas gastronômicas em línguas e culturas distintas revelam diferenças que devem ser levadas em consideração na tradução.

Como expomos nesta seção, a crítica, e mais especificamente a crítica gastronômica, é um gênero textual usado para fins culturais e sociais específicos. Devido a essa especificidade, esses textos naturalmente abarcam um conjunto único de termos e fraseologias, o que justifica a elaboração e manutenção de obras terminológicas de referência. Na próxima seção,

5 Disponível em: https://www.nytimes.com/2016/10/05/dining/dim-sum-joy-luck-palacechinatown.html. Acesso: 15 abr. 2019.

${ }^{6}$ Em tradução livre: "Todos os dias, centenas de porquinhos são levados por um salão tão grande que deixaria muitos aeroportos no chinelo. Parece milagre que algum deles consiga chegar ao outro lado sem ser surrupiado, mas as moças dos carrinhos dão um jeito, como Jesus multiplicando pães e peixes."

TradTerm, São Paulo, v.37, n. 2, janeiro/2021, p. 430-459

Número Especial - Linguística de Corpus

www.revistas.usp.br/tradterm 
apresentamos considerações teóricas que guiaram a elaboração do nosso glossário.

\section{Tradução funcional de textos gastronômicos: terminologia em contexto}

No par de línguas português-inglês, materiais especializados abrangentes e confiáveis na área da culinária ainda são escassos. Agravada pelo fato de ser constantemente relegada a amadores, a tarefa de traduzir e redigir textos gastronômicos em língua inglesa revela falta de padronização na escolha dos equivalentes de referências culturais, ausência de naturalidade, definições inconsistentes, descaracterização de elementos culturais e até mesmo erros grosseiros, que, obviamente, prejudicam a compreensão do leitor (REBECHI 2015; REBECHI, TAGNIN 2020). Como qualquer ato tradutório, a tradução de textos especializados vai muito além da questão da transposição de códigos de uma língua para outra, e envolve diversas variáveis, que, segundo Azenha (1999: 22), “[...] estão intimamente ligadas a uma realidade histórico-cultural e são condicionadas por normas sociais e de uso linguístico, sujeitas a constantes alterações nas diferentes comunidades, em diferentes momentos de tempo".

Ainda que constantemente atualizados e providos de exemplos contextualizados, dicionários de língua geral, assim como glossários especializados, não conseguem atender à grande quantidade de novos conceitos que a globalização, impulsionada pela internet, transporta de uma língua e cultura para outra. Por ser rica em marcadores culturais, a culinária apresenta muitos desafios para o tradutor. E muito além da fidelidade à equivalência, o tradutor deve almejar a lealdade à função do texto de chegada e, consequentemente, ao seu público-alvo (NORD 2006).

Naturalmente, há outras questões relativas à publicação da tradução que independem dos equivalentes sugeridos pela obra de referência. Por exemplo, a limitação de espaço e a adequação ao público-alvo do periódico também terão impacto no texto. Contudo, um glossário que objetive auxiliar o tradutor na

TradTerm, São Paulo, v.37, n. 2, janeiro/2021, p. 430-459

Número Especial - Linguística de Corpus

www.revistas.usp.br/tradterm 
produção de um texto que funcione na língua de chegada de forma tão adequada quanto o texto de partida funcionou com seu público-alvo (NORD 2012) deve considerar as convencionalidades do gênero textual nas diferentes línguas e culturas (TAGNIN 2013).

Segundo Tognini-Bonelli (2001), para alcançar a equivalência, o primeiro passo é identificar unidades de significado funcionalmente completas na língua de origem e, em seguida, encontrar o padrão convencional que transmite o mesmo significado, ou o mais próximo possível, na língua de chegada. Como mencionamos na introdução, nosso glossário visa apresentar termos e fraseologias em português e seus equivalentes funcionais em inglês. Vale ressaltar que, não desconsiderando as diversas composições e nomeações de combinações frequentes de palavras - colocações, n-gramas, clusters, lexical bundles etc. -, nesta pesquisa, adotamos o termo fraseologia para designar coocorrências de palavras características das críticas gastronômicas com o intuito de simplificar a consulta à obra terminográfica. Para elaborar tal glossário, consideramos as questões sobre fidelidade, lealdade e convencionalidade, descritas nos parágrafos anteriores, e apoiamo-nos em uma análise pragmática, subjacente à LC. Na próxima seção, explicamos como a LC orientou o procedimento de levantamento de termos e fraseologias e de busca por equivalentes funcionais.

\section{Compilação e processamento semiautomático do corpus de estudo}

A fim de levantarmos os termos e as fraseologias características das críticas gastronômicas em português, assim como seus equivalentes funcionais em língua inglesa, recorremos aos pressupostos da LC. Definida por McEnery e Hardie (2012: 1) como "[...] área que enfoca um conjunto de procedimentos ou métodos para o estudo da língua [...]”, ${ }^{7}$ a LC envolve a compilação e exploração

\footnotetext{
${ }^{7}$ No original: "[...] area which focuses upon a set of procedures, or methods, for studying language $[\ldots]$ ".
}

TradTerm, São Paulo, v.37, n. 2, janeiro/2021, p. 430-459

Número Especial - Linguística de Corpus

www.revistas.usp.br/tradterm 
de conjuntos de textos (corpora) coletados segundo critérios bem definidos e armazenados de forma que sejam processáveis por computador (BERBER SARDINHA 2004; Bowker, Pearson 2002; TAGnin 2013; entre outros). Uma metodologia baseada em LC possibilita a pesquisa em textos autênticos da área de interesse, a análise de grandes quantidades de dados, o levantamento automático de candidatos a termos e seus colocados, assim como combinações recorrentes (clusters), além de facilitar a busca por equivalentes convencionais em diferentes áreas de especialidade. Todos esses dados, levantados com a ajuda de uma ferramenta computacional, são posteriormente validados (ou não) pelo pesquisador, ou seja, pressupõe-se uma análise semiautomática.

\subsection{O corpus de estudo: coleta}

Em relação a textos que fornecem informações sobre restaurantes e estabelecimentos afins, podemos distinguir dois tipos: aqueles que se limitam aos dados factuais, como tipo de comida servida, horário de funcionamento, faixa de preço, localização, forma de pagamento etc. - conhecidos no meio jornalístico como resenhas -, e aqueles que, além dessas informações, apresentam uma avaliação, em diferentes níveis de detalhamento, com foco na comida, no ambiente e no serviço - denominados resenhas críticas ou críticas gastronômicas. Nesta pesquisa, utilizaremos a denominação crítica gastronômica, a fim de evitar confusão entre os termos.

Normalmente encontradas em revistas e jornais, impressos ou on-line, as críticas, quando avaliam restaurantes e estabelecimentos afins, compreendem o relato da experiência vivida pelo crítico gastronômico, que apresenta argumentos para justificar sua impressão e, muitas vezes, atribui uma nota ou conceito ao local. Esse gênero textual norteou a construção do corpus de estudo.

Para a elaboração do glossário, foi compilado um corpus comparável português-inglês de críticas gastronômicas extraídas de jornais e revistas disponíveis on-line. Partimos da compilação das críticas em português, realizada entre outubro de 2016 e fevereiro de 2017. Durante esse período,

TradTerm, São Paulo, v.37, n. 2, janeiro/2021, p. 430-459

Número Especial - Linguística de Corpus

www.revistas.usp.br/tradterm 
constatamos a dificuldade de coletar textos desse gênero em português brasileiro. Inicialmente, privilegiamos as críticas publicadas em jornais e revistas de grande tiragem, escritas por críticos gastronômicos. Avaliações de usuários, como aquelas que compõem o site TripAdvisor, podem servir para pesquisas acadêmicas, conforme observado em Fuchs (2018), que analisou avaliações de hotéis publicadas por hóspedes nesse site. Mas, considerando a questão da credibilidade discutida acima, optamos por, ao menos a princípio, priorizar as avaliações de restaurantes assinadas por profissionais da área.

Essa busca nos levou aos jornais $O$ Globo, A Folha de São Paulo, O Estado de São Paulo, Jornal Estado de Minas e Super Notícia, além das revistas Prazeres da Mesa e Veja (Rio, São Paulo, Belo Horizonte e Brasília). Notamos, contudo, que, além de limitarem o número de acessos a não assinantes, esses periódicos nem sempre publicam críticas gastronômicas de forma regular. Ao longo do período destinado para a coleta, observamos que não seria possível chegar a um número de palavras considerado adequado para os fins da pesquisa, que almeja a identificação de padrões linguísticos. Por isso, decidimos incluir também avaliações publicadas no jornal Zero Hora e produzidas pelo Destemperados, um coletivo de 100 amantes da gastronomia que relatam suas experiências gastronômicas. Assim, para a construção do subcorpus em português rompemos com o critério previamente estabelecido - o de utilizar apenas críticas de especialistas -, e replicamos a decisão na coleta do subcorpus em inglês, a fim de mantermos o balanceamento do corpus comparável.

Já a montagem do subcorpus em inglês não implicou grandes dificuldades. Vários são os jornais de grande tiragem que publicam críticas gastronômicas e permitem maior acesso a elas. Para o subcorpus em inglês, portanto, pudemos incluir críticas publicadas em jornais de diferentes regiões dos Estados Unidos - Chicago Tribune, Detroit Free Press, Dallas News, Houston Chronicle, Los Angeles Times, The Miami Herald, The Washington Post e The New York Times. E, com a finalidade de equilibrar os dois subcorpora, incluímos, também, avaliações assinadas pelo $C T$ Bites, um grupo estadunidense que atua de modo semelhante ao brasileiro Destemperados. A Tabela 1 resume o corpus de estudo:

TradTerm, São Paulo, v.37, n. 2, janeiro/2021, p. 430-459 Número Especial - Linguística de Corpus www.revistas.usp.br/tradterm 
Tabela 1 - Tamanho do corpus de estudo.

\begin{tabular}{llll}
\hline Subcorpus de críticas em português & Subcorpus de críticas em inglês \\
\hline $\mathrm{N}^{\circ}$ de textos & $\begin{array}{l}\mathrm{N}^{\circ} \text { palavras } \\
\text { (tokens) }\end{array}$ & $\mathrm{N}^{\circ}$ de textos & $\begin{array}{l}\mathrm{N}^{\circ} \text { palavras } \\
\text { (tokens) }\end{array}$ \\
\hline 834 & 334.625 & 338 & 335.053 \\
\hline
\end{tabular}

Fonte: Autoria nossa.

Para atingir um número semelhante de palavras em ambos os subcorpora, o subcorpus em português demandou mais do que o dobro dos textos em inglês norte-americano. Essa diferença entre as duas línguas e culturas não está restrita ao gênero crítica gastronômica, mas corrobora as considerações de Rebechi e Moura (2018), que analisam obituários, Fuchs (2018), que compara avaliações de hotéis por brasileiros e estadunidenses, e Navarro (2011), em sua investigação de sites de hotéis no Brasil e nos Estados Unidos.

Retomando o conceito de contexting do antropólogo Edward Hall, Katan (1999: 177) sugere que “[...] indivíduos, grupos e culturas (e em diferentes momentos) possuem prioridades divergentes no que tange à quantidade de informação (texto) necessária a ser explicitada para que a comunicação seja bem-sucedida". ${ }^{8}$ É denominada high context a cultura que, durante a comunicação, apoia-se em grande medida no conhecimento compartilhado pelo grupo; já em uma cultura low context, supõe-se que o senso comum seja insuficiente para garantir a comunicação, demandando maior explicitação.

Apesar de ser relativamente pequeno, se comparado a corpora de bilhões de palavras com propósitos lexicográficos, como, por exemplo, o Corpus of

\footnotetext{
${ }^{8}$ No original: "[...] individuals, groups, and cultures (and at different times) have differing priorities with regard to how much information (text) needs to be made explicit for communication to take place."
}

TradTerm, São Paulo, v.37, n. 2, janeiro/2021, p. 430-459

Número Especial - Linguística de Corpus

www.revistas.usp.br/tradterm 
Contemporary American English (COCA) $)^{9}$ e o Corpus do Português ${ }^{10}$, nosso corpus de estudo, devido a sua especificidade, mostrou-se adequado para a construção do glossário português-inglês de termos e fraseologias características de críticas gastronômicas. Contanto que tenham sido construídos criteriosamente, levando-se em consideração o propósito da investigação, corpora (relativamente) pequenos permitem diversas pesquisas em diferentes áreas de especialidade. Koester (2010) aponta como uma das vantagens de pesquisas com corpora especializados pequenos o fato de 0 compilador e o analista serem, em geral, a mesma pessoa; portanto, nesses casos, o grau de familiaridade com o contexto tende a ser maior, permitindo que os dados quantitativos, revelados pela ferramenta de análise textual, sejam complementados por análise manual e qualitativa. Nesta pesquisa ficou comprovada essa vantagem, uma vez que as pesquisadoras têm familiaridade com o tema, quer seja adquirida com outras pesquisas realizadas com textos culinários, quer seja como leitoras assíduas de textos do gênero em questão.

Após a compilação dos subcorpara, conforme descrito nesta seção, passamos para a etapa de levantamento das entradas dos verbetes. Essa etapa é descrita na próxima seção.

\subsection{Levantamento das entradas do glossário}

Utilizando a ferramenta Sketch Engine (KILGARRIFF et al. 2014)11, iniciamos a análise com o levantamento das palavras-chave ${ }^{12}$ simples e compostas do subcorpus em português. Como corpus de referência, selecionamos o Corpus Brasileiro, de língua geral, que contém mais de 800 milhões de palavras. Ajustamos a ferramenta para que considerasse como chave palavras e combinações que ocorressem pelo menos cinco vezes, a fim de evitarmos possíveis idiossincrasias de críticos ou periódicos. Também

\footnotetext{
${ }^{9}$ https: / / www.english-corpora.org/coca/

10 https: / / www.corpusdoportugues.org/

11 A ferramenta pode ser acessada gratuitamente por 30 dias e adquirida no site https://www.sketchengine.eu/. Acesso em: 09 abr. 2019.

${ }_{12}$ Palavras ou combinações de palavras que ocorrem estatisticamente com maior frequência no corpus de estudo do que no corpus de referência.
}

TradTerm, São Paulo, v.37, n. 2, janeiro/2021, p. 430-459

Número Especial - Linguística de Corpus

www.revistas.usp.br/tradterm 
desconsideramos palavras-chave que recorreram em apenas uma das fontes. Optamos pela lematização do corpus; assim, as palavras-chave foram apresentadas em sua forma canônica, dicionarizada: os verbos aparecem no infinitivo e os substantivos e adjetivos, no masculino singular, exceto quando a maioria das ocorrências da palavra aparece em outra forma.

A partir das listas de palavras-chave levantadas automaticamente pela ferramenta Sketch Engine - 4.688 em português ${ }^{13}$-, procedemos à seleção manual daquelas que se tornariam entradas do glossário. Uma vez que a obra se limita a abarcar a terminologia característica de restaurantes em geral, e não de culinárias específicas, nomes próprios e de pratos, de bebidas e ingredientes foram manualmente excluídos. Após essa exclusão, os termos selecionados como entradas foram categorizados levando-se em consideração as características dos três principais elementos avaliados pelos críticos gastronômicos: comida, ambiente e serviço. Incluímos, também, uma quarta categoria, denominada outros, com termos e fraseologias relacionadas a localização, preço, formas de pagamento etc., conforme mostrado no Quadro 1:

\footnotetext{
${ }^{13}$ Ressaltamos que a diferença no número de palavras-chave nos dois subcorpora não significa que haja maior variedade lexical em português. A lematização automática por meio do etiquetador TreeTagger mostrou-se menos eficiente na língua portuguesa, falhando, por exemplo, no agrupamento de verbos em diferentes conjugações.
}

TradTerm, São Paulo, v.37, n. 2, janeiro/2021, p. 430-459

Número Especial - Linguística de Corpus

www.revistas.usp.br/tradterm 
Quadro 1 - Categorização dos itens avaliados nas resenhas.

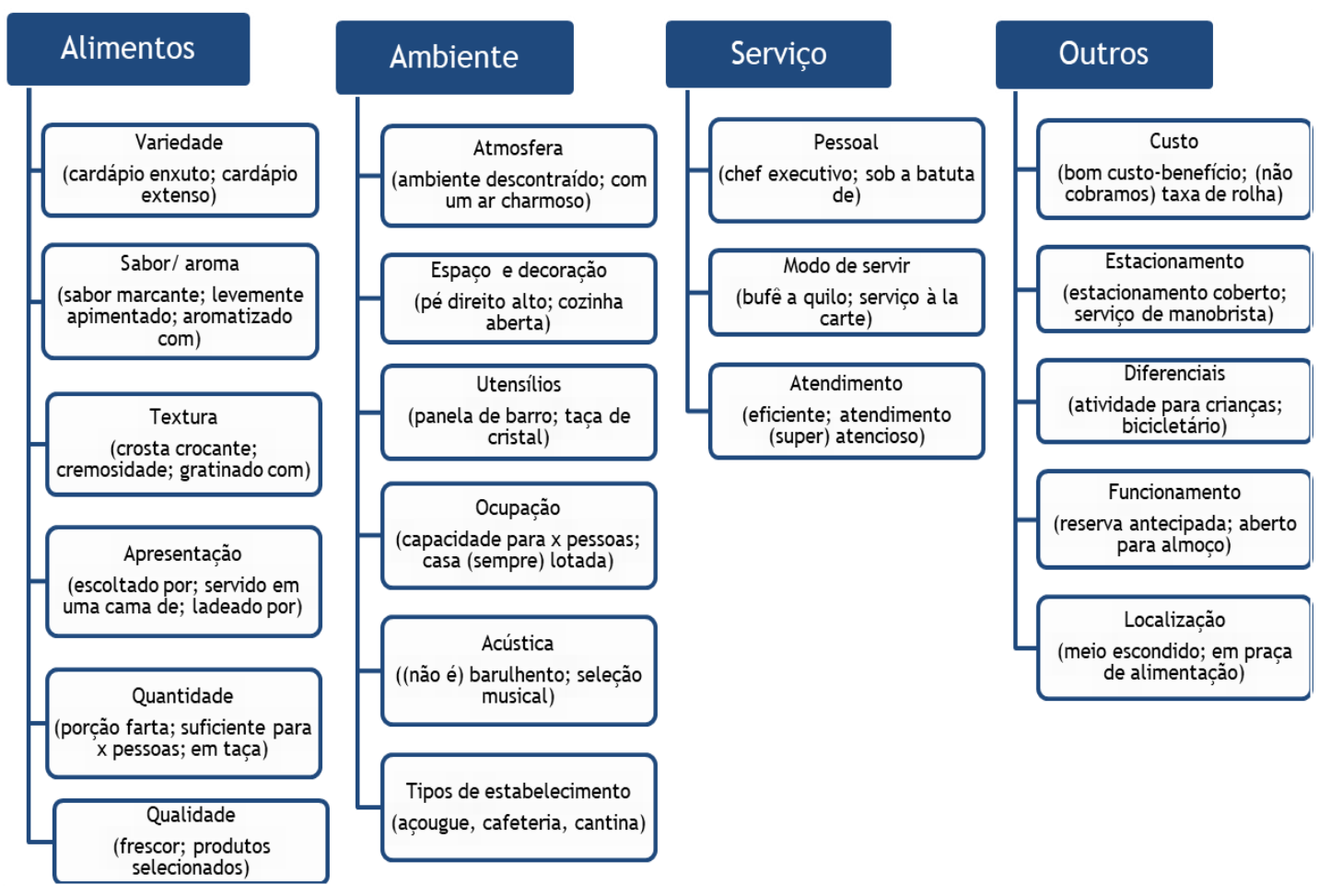

Fonte: Autoria nossa.

A seleção manual das palavras-chave resultou em 1.060 termos - simples e compostos - e fraseologias. Após essa seleção, passamos para a etapa de busca por equivalentes, descrita na próxima seção.

\subsection{A busca por equivalência}

A busca por equivalentes para as entradas em português do glossário se deu no subcorpus em inglês. Para isso, submetemos esse subcorpus ao mesmo processo de análise semiautomática do subcorpus em português, mas utilizando como corpus de referência o enTenTen, disponível no Sketch Engine. Como resultado desse processamento, obtivemos uma lista de 5.372 candidatos a termos e fraseologias em inglês.

A partir da análise das palavras-chave constantes na lista em inglês, buscamos completar o campo equivalente de cada entrada em português. Essa etapa mostrou-se bastante trabalhosa, uma vez que, para nos certificarmos acerca da acepção de determinada palavra ou combinação de palavras no

TradTerm, São Paulo, v.37, n. 2, janeiro/2021, p. 430-459

Número Especial - Linguística de Corpus

www.revistas.usp.br/tradterm 
subcorpus em inglês, foi necessário fazer o levantamento das linhas de concordância, a fim de visualizarmos a palavra em seu contexto de uso. Tomemos como exemplo a palavra-chave courtesy. A princípio, acreditamos tratar-se de palavra cognata e possível equivalente da entrada cortesia (da casa), termo utilizado para se referir à gratuidade de produtos como café, água, pão etc., proporcionada por alguns estabelecimentos. Para comprovar ou refutar essa hipótese, procedemos com o levantamento das linhas de concordância da palavra, conforme apresentado na Figura 1, abaixo:

Figura 1 - Linhas de concordância da palavra de busca courtesy.

\begin{tabular}{|c|c|c|}
\hline 1. & 7.1 has a subtle kick and a lingering aftertaste, & courtesy of a sprinkle of smoked paprika. Though the \\
\hline 2 & , a velvety take with an almost tropical air, & courtesy of coconut milk and a lime leaf gastrique \\
\hline 3. & $<$ text $>$ The catchiest restaurant in Bethesda comes & courtesy of Washington's Mike Isabella, who knows his \\
\hline 4. & nd local deliciousness with a spin of creativity, & courtesy of Sarah Weeden. What began as a quest \\
\hline 5. & capunti blessed with a verdant hue and flavor, & courtesy of arugula worked into the dough, mingle with \\
\hline 6. & cooked to a glorious mush. The bite is & courtesy of Thai chili pepper. Some of my favorite \\
\hline 7 & /tit > Lou Gorfain October 16, 2016 <text $>$ Photo & courtesy of CTWeekender.comAs the name implies, The Corner \\
\hline 8. & (203) 324-2583 Fax:(203) 921-1987 [Photography & courtesy of Jane Beiles Photography] </info > \\
\hline 9 & ich, CT Bistrolatinorestaurant.com [Photography & courtesy of Thomas McGovern Photography] </info > \\
\hline 10 & penTable.com. Soon Cityeats.com [Photography & courtesy of Tom McGovern] </info $>$ \\
\hline 11. & out mentioning the wonderful cocktails we sampled & courtesy of bartender, Chris Grimm. The brushfire, made fr \\
\hline 12 & blanc and a bracing dash of the sea, & courtesy of powdered seaweed. Nova Scotia scallops $(\$ 45)$ w \\
\hline 13 & manzanilla sherry and lavender) and wine service & courtesy of sommelier Greg Schwab. When one of my \\
\hline 14 & culinary tableau unfolds in a re-imagined space, & courtesy of Floyd and Collaborative Projects, that seems $\mathrm{m}$ \\
\hline 15 & live on the menu but come with twists & courtesy of Shepherd and chef de cuisine Nick Fine. \\
\hline
\end{tabular}

Fonte: Autoria nossa.

As linhas de concordância mostram que, no subcorpus em inglês, a palavra de busca courtesy, seguida da preposição of, é utilizada (i) para dar crédito ao trabalho de alguém (linhas $3,4,7,8,9,10,11,13,14$ e 15) e (ii) para se referir ao sabor que determinado ingrediente imprime a uma receita (linhas 1, 2, 5, 6 e 12). Portanto, não se mostra adequada como equivalente funcional de cortesia, mas sim das fraseologias ficar por conta de e graças $a$, ao menos na segunda acepção (ii) identificada. Em relação a um possível equivalente em inglês para a entrada cortesia, não foi identificada contraparte no subcorpus em inglês. Apenas uma ocorrência de free nesse subcorpus resgata o sentido de gratuidade, e se refere ao uso de wi-fi. Naturalmente, não estamos afirmando que esse conceito seja inexistente em língua inglesa, apenas observamos que os estabelecimentos estadunidenses ou não oferecem

TradTerm, São Paulo, v.37, n. 2, janeiro/2021, p. 430-459

Número Especial - Linguística de Corpus www.revistas.usp.br/tradterm 
alimentos ou bebidas gratuitamente, ou tal prática pode ser desconsiderada pelos críticos em suas avaliações ${ }^{14}$. Acreditamos, contudo, que, em casos assim, além de propor um equivalente para o termo, já que esse diferencial pode ser relevante, por exemplo, para um turista estrangeiro em visita ao Brasil, devemos também informar sobre essa diferença cultural em forma de comentário para que o consulente decida se acrescenta a informação ou não, de acordo com a função do texto e o público-alvo que pretende atingir. Por isso, nesse e em outros casos de divergência cultural, incluímos um comentário sobre uso após o exemplo.

Durante esse processo de busca por equivalentes, percebemos que foi necessário usar diferentes estratégias de tradução para garantir a equivalência funcional. Nas próximas subseções, detalharemos o processo de identificação de equivalentes que compõem o glossário.

\subsubsection{Tradução literal}

Entendida como a tradução mais próxima do texto de partida, mas prevendo rearranjos morfossintáticos (CHESTERMAN 1997), nesta pesquisa, entendemos a tradução literal como tradução prima facie, ou seja, estratégia tradutória que, sem comprometer a convencionalidade do texto de chegada, se aproxima da estrutura do texto de partida. A estratégia de tradução prima facie é bastante utilizada e funciona bem quando existe de fato uma tradução padrão ou saliente. Geralmente refere-se àquele equivalente que aparece em primeiro lugar nos dicionários bilíngues. Por isso a utilizamos para a recuperação em português de diversos termos e fraseologias, como almoço $\rightarrow$ lunch, enfeitado com $\rightarrow$ adorned with etc. No entanto, essa estratégia pode não funcionar quando um termo na língua de partida tem duas ou mais possibilidades de tradução de saliência similar, mas que guardam características distintas.

Tomemos como exemplo o termo acompanhamento. A análise das linhas de concordância mostrou que, em português, a palavra pode se referir (i) ao

\footnotetext{
${ }^{14}$ Sabemos por experiência que, dependendo da categoria do estabelecimento estadunidense, é comum o oferecimento de água (da torneira) e café gratuitamente.
}

TradTerm, São Paulo, v.37, n. 2, janeiro/2021, p. 430-459

Número Especial - Linguística de Corpus

www.revistas.usp.br/tradterm 
alimento que acompanha o item principal do prato - por exemplo, as batatas servidas com o peixe; (ii) a outro prato que pode complementar o principal, mas que é pedido separadamente - uma porção de fritas para complementar o filé; e (iii) a pequenas porções (em geral em forma de molhos) que condimentam o elemento principal - vinagrete, mostarda, catchup etc. A análise do subcorpus em inglês revelou três possíveis equivalentes para esse termo, respectivamente, accompaniment, side dish e accoutrement. Dessa forma, abrimos três diferentes entradas para acompanhamento, cada uma com seu respectivo equivalente, além de uma explicação sobre as características do termo, de forma que o tradutor possa escolher qual melhor se aplica ao contexto em questão.

Para manter a convencionalidade do gênero, nem sempre a tradução prima facie se mostra conveniente. Além disso, palavras cognatas podem ter significados distintos em duas línguas, ou não se adéquam aos textos do mesmo gênero nessas duas línguas. Vejamos um exemplo: entre as palavras-chave em português identificamos escoltar, verbo definido em dicionários de língua geral como "acompanhar oferecendo proteção (contra perigos)" e "Manter-se junto de, parado ou se movimentando; acompanhaR" (Aulete Digital 2019). No subcorpus em inglês, recorre o verbo cognato escort. A análise das linhas de concordância mostrou que, em críticas gastronômicas, esses termos não são usados com a mesma acepção nas duas línguas. Escort se refere ao ato de indicar a mesa ao cliente, já escoltar é utilizado para se referir ao(s) acompanhamento(s) do item principal do prato - "(carne) escoltada por (doze tipos de molhos)", "(carpaccio) escoltado por (salada de rúcula)" etc., recuperado em inglês por served alongside, accessorized with e accompanied by/with.

\subsubsection{Tradução por transposição}

Definida como qualquer mudança de classe de palavra durante a tradução (CHESTERMAN 1997), a transposição ocorre porque as línguas têm modos de dizer diferentes; por exemplo, nem sempre um adjetivo na língua de partida

TradTerm, São Paulo, v.37, n. 2, janeiro/2021, p. 430-459

Número Especial - Linguística de Corpus

www.revistas.usp.br/tradterm 
poderá ser recuperado por um adjetivo na língua de chegada. Encontramos em nosso corpus termos e fraseologias em português cujos equivalentes funcionais são formados por estruturas gramaticais diferentes em inglês. Essas diferenças podem ocorrer porque uma das línguas não prevê determinada estrutura gramatical ou porque a estrutura gramatical usada em uma das línguas não é convencional na outra para aquele uso específico. Vejamos um exemplo: entre as palavras-chave em português, observamos o sintagma puxado no (alho/azeite etc.) para se referir à presença marcante - e bem-vinda - do condimento ao elemento principal da receita. Semelhante estrutura não foi identificada em língua inglesa, que resgata o mesmo sentido com o acréscimo do sufixo -y ao substantivo, transformando-o em adjetivo - garlicky, oily, gingery etc.

\subsubsection{Tradução por idiomaticidade}

Durante a análise das palavras-chave nos dois subcorpora, identificamos recorrência de palavras sendo usadas em sentido figurado, na forma de metáforas e idiomatismos. Apresentar um detalhamento das diferenças e semelhanças entre os dois conceitos fugiria ao escopo deste artigo. Aliás, muitos pesquisadores têm se debruçado sobre essa tarefa, sem, contudo, conseguir estabelecer com propriedade seus limites e suas intersecções (ver, entre outros, CSERÉp 2008). Aqui, entendemos expressões idiomáticas e metafóricas como o uso de palavras e sintagmas apartadas de seu sentido literal que, motivadas por questões culturais, históricas, etimológicas etc., perdem a associação com seus referentes originais e ganham novo sentido de acordo com o contexto de uso (TAGNIN 2013). Sendo assim, essas expressões raramente conseguem recuperar o sentido em que foram utilizadas no texto de partida por meio de tradução literal, uma vez que línguas e culturas diferentes fazem analogias distintas entre o sentido literal e o figurado das palavras. Por exemplo, ao afirmar que determinado prato é o carro-chefe do estabelecimento, o crítico, conscientemente ou não, faz menção ao principal carro alegórico do desfile de uma escola de samba para se referir ao prato ou

TradTerm, São Paulo, v.37, n. 2, janeiro/2021, p. 430-459

Número Especial - Linguística de Corpus

www.revistas.usp.br/tradterm 
ingrediente emblemático do restaurante. 0 carnaval, contudo, não corresponde a uma expressão cultural tipicamente estadunidense a ponto de servir como analogia para recuperar esse sentido de importância, ao menos no que tange à linguagem da crítica gastronômica. Observamos, por meio da lista de palavraschave em inglês, que a acepção equivalente é recuperada com expressões que remetem às artes cênicas, como $x$ takes center stage $\mathrm{e} x$ is the star of the show.

\subsubsection{Tradução por paráfrase}

A estratégia da paráfrase é definida por Chesterman (1997) como resultado de uma tradução que prioriza o sentido pragmático, não os componentes semânticos das palavras. Por exemplo, muitas vezes um idiomatismo na língua de partida não pode ser recuperado por um idiomatismo na língua de chegada, ou vice-versa. A análise das palavras-chave nos dois idiomas apontou para um uso mais expressivo de linguagem figurada em inglês, possibilitando inclusive que fraseologias menos idiomáticas na língua de partida sejam recuperadas por idiomatismos em inglês, muito bem-vindos nesse gênero textual. É o caso, por exemplo, da expressão acertar em cheio, utilizada, entre outras, para elogiar o desempenho do cozinheiro. A análise dos termos compostos em inglês revelou que a expressão to knock * out (of) the (ball)park, que remete a um lance bem-sucedido no beisebol, recupera a mesma ideia de forma mais idiomática, e foi utilizada como proposta tradutória no glossário.

\subsubsection{Tradução por implicitação/explicitação}

Observamos que alguns conceitos, apesar de existentes nas duas línguas e culturas, não foram utilizados na mesma proporção nos dois subcorpora. Para exemplificar, vejamos o termo ar-condicionado, que ocorre 181 vezes no subcorpus em português, enquanto sua contraparte em inglês, air-conditioning, ocorre apenas duas vezes. Com base em nosso conhecimento sobre os Estados Unidos, um país rico e desenvolvido, é sensato supor que a baixa frequência do termo não signifique a inexistência dessa comodidade aos clientes, mas sim que

TradTerm, São Paulo, v.37, n. 2, janeiro/2021, p. 430-459

Número Especial - Linguística de Corpus

www.revistas.usp.br/tradterm 
Ihes oferecer um ambiente climatizado é pressuposto nesses estabelecimentos. Em relação ao Brasil, sabemos por experiência que é comum encontrar estabelecimentos sem ar-condicionado. Possivelmente por isso os críticos julguem relevante mencionar o item nas suas avaliações, já que é um ponto positivo e que agrega valor. Para garantir que os usuários do glossário possam decidir entre deixar essa informação implícita ou explícita, dependendo da recepção esperada para o texto de chegada, o verbete, além do equivalente, inclui um comentário apontando a diferença entre as duas culturas.

\subsubsection{Tradução por empréstimo}

Alguns conceitos são tão culturalmente específicos que não encontram equivalência na língua e na cultura de chegada. A fim de preservar o estranhamento (cf. VENUTI 2005) do marcador cultural, propomos transferi-lo diretamente, pois a adaptação por algum elemento semelhante poderia acarretar a perda dos traços distintivos do termo original. É o caso de barzinho, estabelecimento tipicamente brasileiro, com ambiente descontraído, muitas vezes com música ao vivo, onde são servidos bebidas e pratos simples. Apesar de, obviamente, não haver ocorrência desse tipo de estabelecimento no subcorpus em inglês, apresentamos o empréstimo como sugestão de equivalência, seguido de uma definição (cf. REBECHI \& TAGNIN 2020), que pode ou não ser utilizada pelo tradutor ou redator, dependendo da função do texto em inglês.

\subsubsection{Tradução por filtro cultural}

Chesterman (1997) afirma que a tradução por filtro cultural, também chamada domesticação ou naturalização, consiste em traduzir itens da língua de partida adaptando-os à cultura e à função na língua de chegada. A análise manual das duas listas revelou práticas culturais que não permeiam as duas línguas e culturas, mas que possuem alguns traços semelhantes. Nesses casos, sugerimos a naturalização como equivalente funcional, mas alertamos o consulente para as diferenças entre os dois conceitos, em forma de comentário.

TradTerm, São Paulo, v.37, n. 2, janeiro/2021, p. 430-459

Número Especial - Linguística de Corpus

www.revistas.usp.br/tradterm 
Observamos, por exemplo, alta frequência do termo atividades para crianças e family-friendly, nos subcorpora em português e em inglês, respectivamente. Trata-se de duas práticas distintas - no Brasil, é um diferencial do estabelecimento reservar uma área para recreação, muitas vezes sob a supervisão de um monitor que entretém as crianças enquanto os pais aproveitam a refeição. Em um país com uma cultura tradicionalmente tão litigiosa quanto os Estados Unidos, é fácil entender por que um estabelecimento não assumiria a responsabilidade por possíveis contratempos. Lá, contudo, é costume indicar que crianças são bem-vindas, até mesmo como forma de alertar os clientes que estejam buscando um lugar tranquilo, por exemplo.

Tratamos, acima, das principais estratégias tradutórias adotadas na tentativa de fornecer ao consulente a melhor forma de resgatar conceitos característicos de críticas gastronômicas brasileiras em língua inglesa por meio de uma metodologia apoiada na autenticidade dos textos nos dois idiomas. Mostramos, também, que a tradução funcional nem sempre se dá pelo resgate de termo por termo ou fraseologia por fraseologia, uma vez que as línguas diferem gramatical e morfologicamente. Conforme afirma Firth (1957: 11), as palavras andam juntas, formando colocações. Seguindo essa premissa, preocupamo-nos com a melhor forma de apresentar equivalentes e exemplos de uso de forma a conduzir o consulente a usá-los de forma convencional na língua de chegada. A seguir, apresentamos a estrutura do glossário, com ênfase no campo equivalente.

\section{O glossário}

Com vistas a construir uma obra terminográfica que auxilie tradutores e redatores na produção de textos da área da gastronomia, especialmente críticas e cardápios, utilizamos o software TshwaneLex ${ }^{15}$ (TLex), que consiste em um conjunto de aplicativos para construção e gerenciamento de materiais

\footnotetext{
${ }^{15}$ Disponível para aquisição em: http://tshwanedje.com/. Acesso em: 07 fev. 2020.

TradTerm, São Paulo, v.37, n. 2, janeiro/2021, p. 430-459

Número Especial - Linguística de Corpus

www.revistas.usp.br/tradterm
} 
terminográficos e lexicográficos e que permite a exportação do arquivo finalizado para várias formatações, entre elas HTML, RTF e XML. Para servir aos propósitos da pesquisa aqui descrita, customizamos a ferramenta para que os verbetes tivessem como elementos essenciais entrada, categoria gramatical, equivalente, exemplo de uso e fonte de extração do exemplo (em forma de URL), e, como elementos eventuais, definição, comentário e remissiva. Em seguida, detalhamos os elementos fundamentais ao tradutor.

\subsection{Entradas do glossário}

As entradas, selecionadas a partir das listas de palavras-chave geradas automaticamente, estão dispostas em ordem alfabética. Consistem em termos simples e compostos, além de colocações recorrentes com o termo, sempre privilegiando a forma como o termo aparece com maior frequência nos textos autênticos. Por exemplo, apresentamos as entradas acompanhar e acompanhado de/por [(ser/vir)]. Em apresentação à obra, o usuário será informado que (i) a barra separando palavras indica que mais de uma estrutura é possível; (ii) os parênteses expressam o uso eventual de determinada palavra; e (iii) os colchetes representam a inversão da ordem entre o elemento gramatical - verbo auxiliar, preposição, artigo etc. - e o termo. Assim, apenas palavras de conteúdo - verbo principal, substantivo e adjetivo - iniciam as entradas, como forma de facilitar a consulta.

É importante ressaltar que uma entrada pode apresentar mais de um equivalente, e que esses podem consistir em sinônimos ou em diferentes estruturas de um mesmo lema, contanto que sejam recorrentes no subcorpus em inglês. Observamos, por exemplo, que a combinação afogado(a) em, utilizada para mencionar uso excessivo de algum elemento na receita, pode ser resgatado em inglês por soaked in, saturated with e smothered in, ou pela estrutura *-soaked, como em wine-soaked clam. Nesses casos, ambas as estruturas são fornecidas ao consulente, como no Exemplo 1, abaixo, que apresenta os equivalentes mais recorrentes no subcorpus em inglês em ordem decrescente:

TradTerm, São Paulo, v.37, n. 2, janeiro/2021, p. 430-459 Número Especial - Linguística de Corpus www.revistas.usp.br/tradterm 
Exemplo 1: afogado em (fras.) soaked in, *-soaked, saturated with, smothered in

0 asterisco utilizado em *-soaked representa a possibilidade de preenchimento com diferentes substantivos para formar uma expressão hifenizada, muito comum em língua inglesa, como em pork-filled spring roll e caramel-topped puddings. Um glossário que apresente simplesmente os equivalentes dicionarizados dos lemas afogar, rechear e cobrir, por exemplo, certamente não contribuiria para garantir a convencionalidade desse gênero textual em língua inglesa.

\subsection{Exemplo(s) de uso}

O uso de exemplos como ferramenta de auxílio à tradução foi testado e aprovado no estudo de Frankenberg-Garcia (2015), com a aplicação de tarefas tradutórias a grupos que tinham acesso a exemplos e grupos que não contavam com esse subsídio. Uma vez que partimos de textos autênticos para a coleta dos termos do nosso glossário, consideramos importante também fornecer ao consulente a contextualização desses elementos a fim de auxiliá-los na redação em língua inglesa. A partir das linhas de concordância com os equivalentes selecionados em inglês, buscamos exemplos ilustrativos que complementassem a interpretação do significado e ajudassem o consulente a usar o termo ou fraseologia na língua estrangeira. Vejamos o Exemplo 2:

Exemplo 2: agradar ao paladar (de) (fras.) accommodate sb's palate//Ex.: [...] if vegan or vegetarian is not your bag, they will and can accommodate any palate. [http://www.ctbites.com/blog/2016/11/6/the-granola-bar-healthyeats-coffee-in-greenwich.html]

Ao apresentar a oposição entre as possíveis preferências alimentares dos clientes, o contexto ajuda a explicar que todos serão atendidos e ficarão satisfeitos. Caso o consulente necessite ver a frase em contexto completo, poderá seguir o link para o texto na íntegra, caso ainda esteja ativo.

TradTerm, São Paulo, v.37, n. 2, janeiro/2021, p. 430-459 Número Especial - Linguística de Corpus www.revistas.usp.br/tradterm 


\subsection{Definição}

Redigidas em língua inglesa, as definições têm o propósito de funcionar como um aposto explicativo (Cf. REBECHI \& TAGNIN 2020) para elementos culturais brasileiros que não possuem equivalentes consagrados na língua estrangeira. Com esse item, pretendemos oferecer ao consulente a possibilidade de incluir, caso julgue adequado, uma explicação sobre o referente cultural no texto em inglês, considerando sua função. 0 Exemplo 3 ilustra essa estratégia no verbete barzinho, indicando que o consulente pode ver também (v.t.) a remissiva bar, caso deseje distinguir os termos:

Exemplo 3: barzinho (s.) barzinho A typical Brazilian bar with a convivial and relaxed environment where couples or small parties meet in the evening to listen to soft (usually) live music, to drink and to have appetizers. v.t. bar

\subsection{Comentário}

Esse elemento é acrescentado em português para explicar diferenças entre as duas línguas-culturas, possibilitando que o tradutor ou redator tome decisões sobre a necessidade de resgate na língua de chegada. Além do caso do ar-condicionado, citado anteriormente, couvert também se mostrou recorrente apenas no subcorpus em português. Portanto, para essa entrada propomos que o equivalente se dê por empréstimo, e incluímos um comentário, conforme exemplo abaixo:

Exemplo 4: couvert (s.) couvert An assortment of bread and spreads that is offered for an extra cost before you order.// Nenhum equivalente encontrado no corpus em inglês, possivelmente devido a diferenças culturais. Assim como em outros países, no Brasil o couvert geralmente é oferecido como forma de o estabelecimento ter um lucro extra. Já nos EUA essa prática não é comum. Portanto, propomos uma tradução por empréstimo.

TradTerm, São Paulo, v.37, n. 2, janeiro/2021, p. 430-459

Número Especial - Linguística de Corpus

www.revistas.usp.br/tradterm 
Além dos elementos detalhados acima, o glossário conta com sistema de remissivas para conduzir o consulente a outras entradas que complementam as informações do termo - no formato "ver também" - e sinônimos - "mesmo que".

Denominado Dicionário Gastronômico ${ }^{16}$, o material de livre acesso está disponível em formato eletrônico na direção português-inglês ${ }^{17}$ pelo endereço https://www.ufrgs.br/dicionariogastronomico/. A Figura 2 ilustra o verbete vontade de [ficar com] no site:

Figura 2 - Visualização de entrada do glossário no site.

\section{Considerações finais}

Criamos nosso glossário com o objetivo de auxiliar o consulente na tarefa de traduzir ou redigir críticas gastronômicas e cardápios de forma funcional e convencional em inglês e em português. A Linguística de Corpus, ao longo da pesquisa, provou-se essencial para a construção do glossário, já que possibilita a extração de termos e fraseologias recorrentes no gênero textual crítica

\footnotetext{
${ }^{16}$ Optamos por nomear a obra terminográfica dicionário por julgarmos que este tem mais apelo entre os possíveis consulentes.

170 material de referência na direção inglês-português está em fase de finalização e em breve estará disponível no mesmo endereço.
}

TradTerm, São Paulo, v.37, n. 2, janeiro/2021, p. 430-459

Número Especial - Linguística de Corpus

www.revistas.usp.br/tradterm 
gastronômica e a identificação de equivalentes funcionais na língua de chegada, permitindo que o tradutor ou redator garanta a convencionalidade no texto de partida.

Nossa busca por equivalentes evidenciou as diferenças que existem entre as duas línguas e culturas com as quais trabalhamos, pois nem todos os termos e combinações de palavras que extraímos dos subcorpora tinham equivalentes em sua contraparte. Na maioria das vezes, isso resultava, claramente, das diferenças culturais entre o Brasil e os EUA.

Esperamos, com as traduções propostas no material terminográfico, oferecer alternativas convencionais para a redação de textos gastronômicos em língua estrangeira ou para traduzi-los de forma funcional.

TradTerm, São Paulo, v.37, n. 2, janeiro/2021, p. 430-459

Número Especial - Linguística de Corpus

www.revistas.usp.br/tradterm 


\section{Referências}

AdLER, J. A review to die for? Newsweek. 09/03/2003. Web. 2 abr. 2019. <https://www.newsweek.com/review-die-132553>

Aulete Digital. Dicionário. Web. 26 abr. 2019. <http://www.aulete.com.br/escoltar>

AZENHA JR., J. Tradução técnica e condicionantes culturais: primeiros passos para um estudo integrado. São Paulo: Humanitas, 1999.

Berber Sardinha, T. Lingüística de corpus. Barueri: Manole, 2004.

BIBER, D.; CONRAD, S.; CORTES, V. If you look at...: Lexical bundles in university teaching and textbooks. Applied linguistics, v. 25, n. 3, p. 371-405, 2004.

BIBER, D.; BARBIERI, F. Lexical bundles in university spoken and written registers. English for specific purposes, v. 26, n. 3, p. 263-286, 2007.

BIRD, B. Ratatouille. Walt Disney Pictures/Pixar Animation Studios. 2007. DVD.

BLANK, G. Critics, ratings, and society: The sociology of reviews. Lanham: Rowman \& Littlefield Publishers, 2007.

BOWKER, L.; PEARSON, J. Working with specialized language: a practical guide to using corpora. London/New York: Routledge, 2002.

CAPATTI, A.; MONTANARI, M. La cucina italiana: storia di una cultura. Gius. RomaBari: Editora Laterza, 1999. Impresso

Chesterman, A. Memes of Translation: The Spread of Ideas in Translation Theory. Amsterdam-Philadelphia: John Benjamins, 1997.

CSERÉP, A. Idioms and metaphors. In: ANDOR, J.; Hollósy, B.; LACZKó, T.; PelyVÁs, P. (ed.) When grammar minds language and literature: Festschrift for Prof. Béla Korponay on the Occasion of His 80th Birthday, Debreceni Egyetem Angol és Amerikai Tudományok Intézete, 2008, pp. 85-94.

FIRTH, J. R. A synopsis of linguistic theory, 1930-1955., In: FIRTH, J. R. (ed.) Studies in linguistic analysis. Oxford: Blackwell, 1957: 1-32.

FRANKENBERG-GARCIA, A. Dictionaries and encoding examples to support language production. International Journal of Lexicography 28.4 (2015): 490512. Web. $20 \quad$ abr. 2019. https: / /academic.oup.com/ijl/article/28/4/490/2413091>

FuCHS, S. N. Orientações culturais e suas implicações para a tradução funcionalista: um estudo na área do turismo à luz da Linguística de Corpus. Tese. Universidade de São Paulo, 2018. Web. 20 abr. 2019. < http: //www.teses.usp.br/teses/disponiveis/8/8160/tde-27082018165601/es.php>

TradTerm, São Paulo, v.37, n. 2, janeiro/2021, p. 430-459

Número Especial - Linguística de Corpus www.revistas.usp.br/tradterm 
Gerhardt, C.; Frobenius, M.; Ley, S. (ed.) Culinary Linguistics: the chef's special. Amsterdam/Philadelphia: John Benjamins Publishing, 2013.

JUNQUEIRA, L. A genre-based investigation of applied linguistics book reviews in English and Brazilian Portuguese. Journal of English for Academic Purposes 12.3 (2013): 203-213. Web. 22 abr. 2019. < https://www.sciencedirect.com/science/article/pii/S14751585130004 $\underline{28}>$

JURAFSKY, D. The language of food: A linguist reads the menu. New York: W. W. Norton \& Company, 2014.

KATAN, D. Translating cultures: an introduction for translators, interpreters and mediators. Manchester: St. Jerome, 1999.

KILGARRIFF, A. ET AL. The Sketch Engine: ten years on. Lexicography 1.1 (2014): 7-36. Web. $22 \quad$ abr. 2019.

https: / /link.springer.com/article/10.1007/s40607-014-0009-9>

Koester, A. Building small specialised corpora. In: O’KeEfFE, A.; MCCARTHy, M. (ed.) The Routledge handbook of Corpus Linguistics. New York: Routlege, 2010. p. 66-79.

MCEnery, T.; HARDIE, A. Corpus linguistics: Method, theory and practice. Edinburgh: Cambridge University Press, 2012.

Nagle, M. At Joy Luck Palace, Dim Sum Amid the Chaos. The New York Times. 29/09/2016. Web. $\quad 4 \quad$ abr. 2019 <https://www.nytimes.com/2016/10/05/dining/dim-sum-joy-luckpalace-chinatown.html?ref=dining\&_ $r=0>$

NAVARRo, S. L. M. Glossário bilíngue de colocações da hotelaria: um modelo à luz da Linguística de Corpus. Dissertação. Universidade de São Paulo, 2011. Web. 20 abr. 2019.

NoRd, C. Functional Approaches to Translation. In: ChAPELLE, C. A. (org.). The Encyclopedia of Applied Linguistics. Hoboken: Blackwell Publishing, 2012, pp. 2223-2228. Web. 22 abr. 2019. < https: / / onlinelibrary.wiley.com/doi/full/10.1002/9781405198431.wb eal0442>

NoRD, C. Loyalty and Fidelity in Specialized Translation. Confluências, n. 4, p. 29-42, maio 2006. Web. 26 abr. 2019. < https://www.academia.edu/12701555/Loyalty_and_Fidelity_in_Speci alized_Translation>

Pudlowski, G. Para que serve um crítico gastronômico? Trad. Constância Morel. São Paulo: Edições Tapioca, 2012.

REBECHI, R. R. A Tradução da Culinária Típica Brasileira para o Inglês: um Estudo sob o Enfoque da Linguística de Corpus. Tese. Universidade de São Paulo, 2015. Web. 20 abr. 2019.

TradTerm, São Paulo, v.37, n. 2, janeiro/2021, p. 430-459

Número Especial - Linguística de Corpus

www.revistas.usp.br/tradterm 
REBECHI, R. R.; MOURA, M. Brazilian recipes in Portuguese and English: the role of phraseology for translation. Computational and Corpus-based Phraseology.1 ed. Cham: Springer, 2017, p. 102-114.

REBECHI, R. R.; MOURA, M. Obituaries in translation: a corpus-based study. Cadernos de Tradução 38.3 (2018): 298-318. Portal de Periódicos da UFSC. 20/04/2018.

https://periodicos.ufsc.br/index.php/traducao/article/view/21757968.2018v38n3p298/37398>

REBECHI, R. R.; TAGNIN, S. E. O. Brazilian cultural markers in translation: a model for a corpus-based glossary. RiCL-Research in Corpus Linguistics, 8 (2020): 65-85. 28/05/2020. https://ricl.aelinco.es/index.php/ricl/article/view/129>

RUIZ, E. M.; FARIA, M. B. A intertextualidade no gênero resenha. Linguagem em $\begin{array}{llll}\text { Discurso } & 12.1 & \text { (2012): } & \text { 99-128. }\end{array}$ <http://www.portaldeperiodicos.unisul.br/index.php/Linguagem_Disc urso/article/view/862/790>

SCHIRA, R. Mangiato bene? As sete regras para reconhecer a boa cozinha. Trad. Eliana Aguiar. Rio de Janeiro: BestSeller, 2015.

SWALES, J. Genre analysis: English in academic and research settings. Cambridge university press, 1990.

TAGNIN, S. E. O. O jeito que a gente diz: combinações consagradas em inglês e português. São Paulo: Disal, 2013.

TEIXEIRA, E. D. A linguística de corpus a serviço do tradutor: proposta de um dicionário de culinária voltado para a produção textual. Tese. Universidade de São Paulo, 2008. Web. 20 abr. 2019. < https: / / www.teses.usp.br/teses/disponiveis/8/8147/tde-16022009141747/pt-br.php>

Temmerman, R.; Dubois, D. (ed.). Food and terminology: expressing sensory experience in several languages. Terminology 23:1, 2017.

Tigner, A. L.; Carruth, Allison. Literature and Food Studies. Abingdon/New York: Routledge, 2017.

TognINI-BonelLI, E. Corpus Linguistics at work. Amsterdam/Philadelphia: John Benjamins, 2001.

VENUTI, L. Local Contingencies: Translation and National Identities. In:

BermanN, S.; WoOD, M. (ed.) Nation, language and the ethics of translation. Princeton e Oxford: Princeton University Press, 2005.

Recebido em: 07/02/2020

Aceito em: 26/05/2020

Publicado em janeiro de 2021

TradTerm, São Paulo, v.37, n. 2, janeiro/2021, p. 430-459

Número Especial - Linguística de Corpus

www.revistas.usp.br/tradterm 